Part of Journal of Research of the National Bureau of Standards, Volume 21, July 1938

\title{
HYDROGEN-REDUCTION METHOD FOR THE DETERMI- NATION OF OXYGEN IN STEEL
}

\author{
By John G. Thompson and Vernon C. F. Holm
}

\section{ABSTRACT}

A modified hydrogen-reduction method yielded accurate values for the total oxygen content of several plain carbon steels, including steels that contained small amounts of alumina and silica, but yielded low results when larger amounts of alumina were present. The method was not applicable to the determination of the oxygen content of open-hearth iron because of inability to separate surface and body oxygen in this material.

I. Introduction

II. Modified hydrogen-reduction procedure

III. Experimental__

IV. Conclusions

\section{INTRODUCTION}

The determination of oxygen in iron and steel and its significance to manufacturers and users of these materials have been matters of interest to metallurgists for many years. A variety of analytical methods have been developed, but the relative merits and accuracy of many of the methods are still controversial questions. The report ${ }^{1}$ of results obtained in the recent cooperative study of methods for the determination of oxygen in steel, sponsored jointly by the National Bureau of Standards and the American Institute of Mining and Metallurgical Engineers, emphasizes the difficulty of obtaining concordant results by different methods and, in many cases, by different operators using the same method. It is evident that further attention must be devoted to this problem both in perfecting the various methods and in studying their limitations before complete reliance may be attached to determinations by any one method.

One of the methods that appears promising is a modified form of the hydrogen-reduction (Ledebur) procedure. In the original Ledebur method the sample was exposed to the action of hydrogen at temperatures above $900^{\circ} \mathrm{C}$; the amount of water vapor recovered from the exit gases was used as a measure of the amount of oxides reduced by the hydrogen and hence of the amount of oxygen in the steel. It was found that low recoveries of oxygen were obtained by this procedure because the carbon of the iron or steel samples enters into the

1 J. G. Thompson, H. C. Vacher, and H. A. Bright, Trans. Am. Inst. Mining Met. Engrs. 125, 246 (1937); J. Research NBS 18, 259 (1937) RP976. 
reduction reactions, and the exit gases therefore contain appreciable amounts of $\mathrm{CO}$ and $\mathrm{CO}_{2}$ as well as water vapor. Procedures were devised for the determination of the oxygen combined as carbon oxides in addition to that combined as water, which materially increased the amounts of oxygen recovered from samples of iron and steel. In the early work it was believed that the use of milled samples or drillings was impracticable because of the presence of appreciable amounts of oxygen in the form of surface films. This trouble was avoided through the use of solid samples to which antimony and tin were added to form alloys that were molten at the temperature of the determination. Although this procedure eliminated the errors due to surface oxygen, it introduced another source of error because of possible reduction of the refractory boat which contained the molten sample.

In 1934 Brower, Larsen, and Shenk ${ }^{2}$ described a modification of the Ledebur method that appears to be a decided improvement over the older procedures. The modified procedure, however, has not as yet been widely adopted; the data of the cooperative analysis ${ }^{3}$ included only one set of determinations by this procedure. The present work was undertaken to obtain more information about the modified hydrogen-reduction procedure, particularly in regard to the reproducibility of its results in the hands of different operators and the comparison of its results with those obtained by other methods of analysis.

\section{MODIFIED HYDROGEN-REDUCTION PROCEDURE}

The essential features of Brower, Larsen, and Shenk's procedure are the use of a finely milled sample, the removal of surface oxygen from the millings by a preliminary heating in hydrogen at 500 to $550^{\circ}$ $\mathrm{C}$, and the use of high-frequency induction heating to maintain the sample at $1,200^{\circ} \mathrm{C}$ for the determination of the "body" oxygen of the millings.

The construction and operation of the apparatus illustrated in figure 1, were essentially as described by Brower, Larsen, and Shenk. Electrolytic hydrogen, from a cylinder of compressed gas, is passed through a preliminary purification train to eliminate moisture and oxygen from the gas before it comes in contact with the sample in the furnace tube. The rate of flow of hydrogen is indicated by bubbler tubes and is maintained at approximately $30 \mathrm{ml}$ per minute. Back diffusion of air is prevented by sulfuric acid bubblers, at all exits. A trap containing about $2 \mathrm{~cm}$ of mercury prevents the development of excessive gas pressures within the apparatus.

The sample consists of approximately $20 \mathrm{~g}$ of fine millings placed in a perforated Invar bucket and suspended in the center of the vertical furnace tube. With purified hydrogen passing through the apparatus, the furnace tube and contents are heated to 500 to $550^{\circ} \mathrm{C}$, by means of a resistance furnace, and are maintained at this temperature for 90 minutes to remove the surface film of oxides and moisture. The hydrogen leaving the furnace during this operation usually is wasted, but, if a determination of surface oxygen is desired, the exit gases may be passed through suitable absorbents to recover the water vapor formed by reduction of the oxides.

${ }_{2}^{2}$ T. E. Brower, B. M. Larsen, and W. E. Shenk, Trans. Am. Inst. Mining Met. Engrs. 113, 61 (1934).

${ }^{3}$ See footnote 1 . 
After "stripping" the surface oxygen from the sample, the resistance furnace is replaced by a high-frequency induction coil, and the temperature of the sample is raised to $1,200^{\circ} \mathrm{C}$ and is maintained at this temperature for 90 minutes to accomplish the reduction of the "body" oxygen in the millings. The water vapor produced by the reduction reactions is absorbed by phosphorus pentoxide in a weighing tube. The stream of hydrogen is subsequently freed from sulfur compounds and passed over a nickel-thoria catalyst maintained at $260^{\circ} \mathrm{C}$, whereby the carbon oxides are quantitatively converted to methane and water vapor, the latter being absorbed in phosphorus pentoxide. The sum of the gains in weight of the two phosphorus pentoxide tubes furnishes a measure of the oxygen liberated from the oxides of the steel.

The efficiency of the nickel-thoria catalyst and the absorbents is checked periodically by a run in which a weighed amount of crystal-

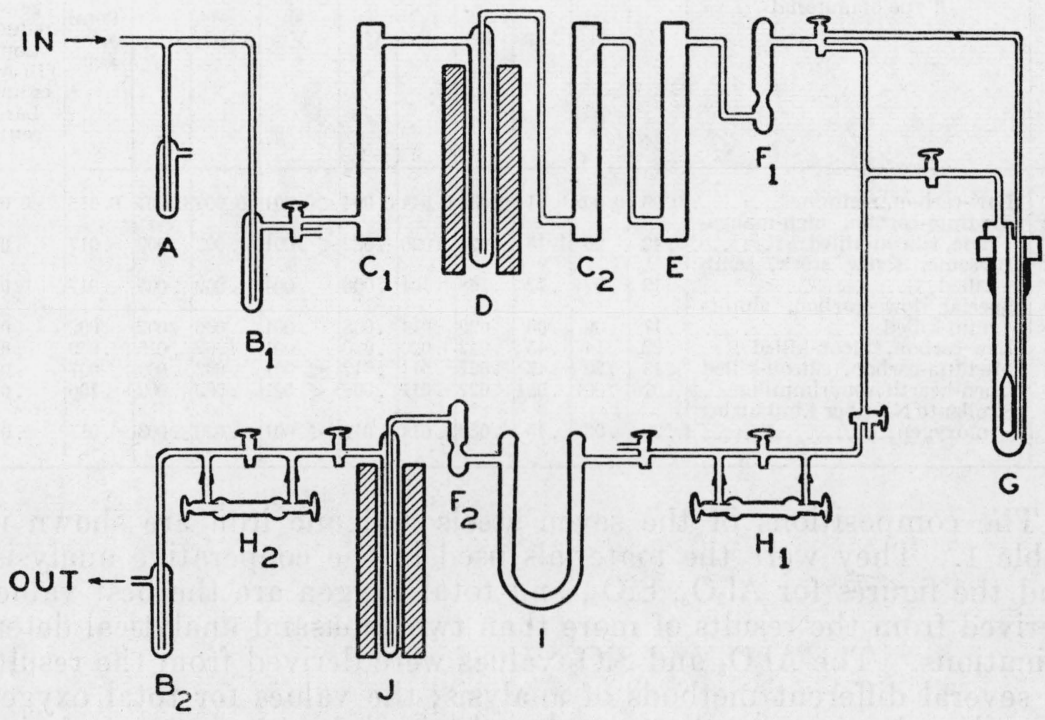

FIGURE 1.-Sketch of the hydrogen-reduction apparatus.

$A$, mercury trap; $B_{1}, B_{2}$, sulfuric acid bubblers $C_{1}, C_{2}$, soda-lime tubes; $D$, platinized silica catalyst; $E$, anhydrone tube; $F_{1}, F_{2}$, phosphorus pentoxide drying tubes; $G$, fused silica furnace tube; $\mathrm{H}_{1}, \mathrm{H}_{2}$, phosphorus pentoxide weighing tubes; $I$, anhydrous copper sulfate on pumice stone; $J$, nickel-thoria catalyst.

line calcite $\left(\mathrm{CaCO}_{3}\right)$, contained in a platinum crucible, is heated gradually to $900^{\circ} \mathrm{C}$ with the hydrogen flowing through the apparatus. Under these conditions the calcite is decomposed with the evolution of water vapor, carbon monoxide, and carbon dioxide which can be recovered in the analytical train in the same manner as during a determination on a sample of millings. The recovery of 95 percent or more of the theoretical amount of oxygen from the calcite indicates satisfactory performance of the apparatus.

Blank determinations on the whole apparatus, with the empty invar bucket at the operating temperature, are made periodically. The blank correction is quite constant at $0.0003 \mathrm{~g}$ of water for a determination of 90 minutes duration. The time required for a complete determination, including the preliminary flushing and the removal of surface oxygen, is approximately 5 hours. 


\section{EXPERIMENTAL}

Determinations of oxygen, by the modified hydrogen-reduction procedure, were made on milled samples of seven steels and one iron. The sample material was prepared in a milling machine that was set for a depth of cut of 0.003 inch, or less. The millings thus produced were between 0.005 and 0.008 inch in thickness, according to micrometer measurements.

TABLE 1.-Type and composition of the materials

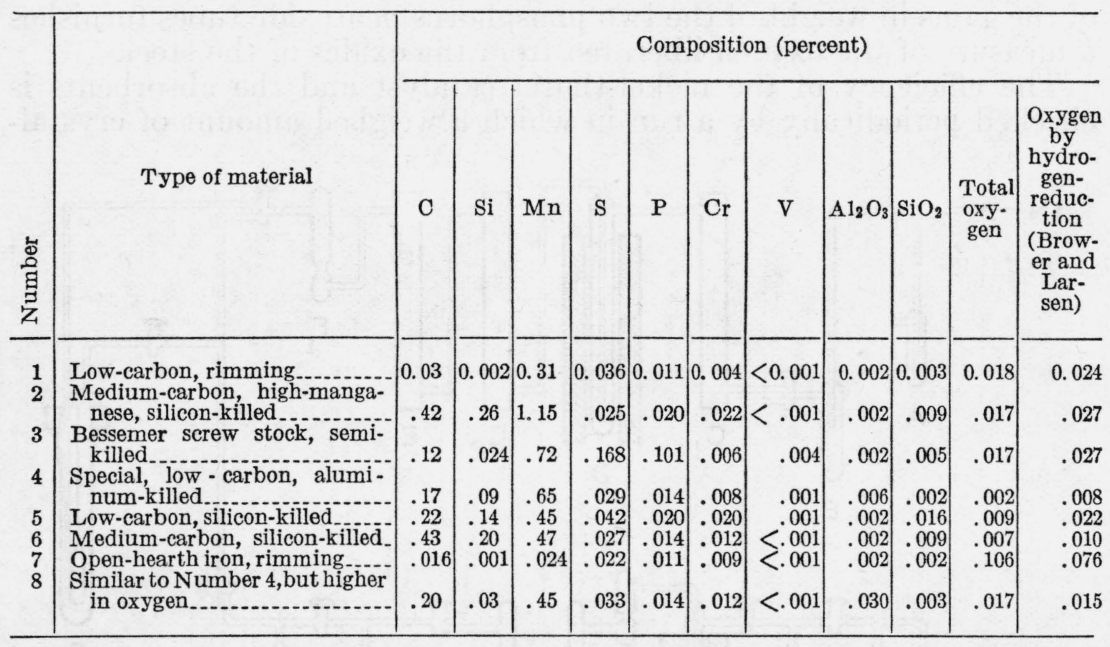

The compositions of the seven steels and one iron are shown in table 1. They were the materials used in the cooperative analysis, and the figures for $\mathrm{Al}_{2} \mathrm{O}_{3}, \mathrm{SiO}_{2}$, and total oxygen are the best values derived from the results of more than two thousand analytical determinations. The $\mathrm{Al}_{2} \mathrm{O}_{3}$ and $\mathrm{SiO}_{2}$ values were derived from the results of several different methods of analysis; the values for total oxygen were based on concordant results obtained by the vacuum-fusion method and in many cases were substantiated by results of other methods. Because of the number of analyses that were made and the variety of methods that were employed, and because the selected values are based on concordance of results obtained by several different methods, the $\mathrm{Al}_{2} \mathrm{O}_{3}, \mathrm{SiO}_{2}$, and total oxygen contents of these steels can be stated with an unusual degree of certainty. The values given in table 1 are close approximations of the actual contents of $\mathrm{Al}_{2} \mathrm{O}_{3}, \mathrm{SiO}_{2}$, and total oxygen, i. e., they are accurate values within the customary limits of tolerance of such determinations and are more reliable than determinations by a single operator or by a single method. The last column in table 1 lists the results reported by Brower and Larsen, in the cooperative analysis, for determinations by the modified hydrogen-reduction procedure.

The values obtained in the present study of the hydrogen-reduction method are shown in table 2 , together with results of determinations by the vacuum-fusion method. The latter were made to compare results on the current samples with those previously obtained on other samples of the same material, and to provide a means for direct 
comparison of results by the vacuum-fusion and hydrogen-reduction procedures when all determinations were made by the same analyst. The apparatus and procedure employed for the vacuum-fusion determinations differ from those described by Vacher and Jordan ${ }^{4}$ in two respects (a) the two-stage mercury diffusion pump that evacuates the furnace has been replaced by a four-stage high-capacity pump and (b) the gases are determined volumetrically, by measuring the pressure in the system before and after each absorption.

TABLE 2.-Determinations of the oxygen contents of eight steels

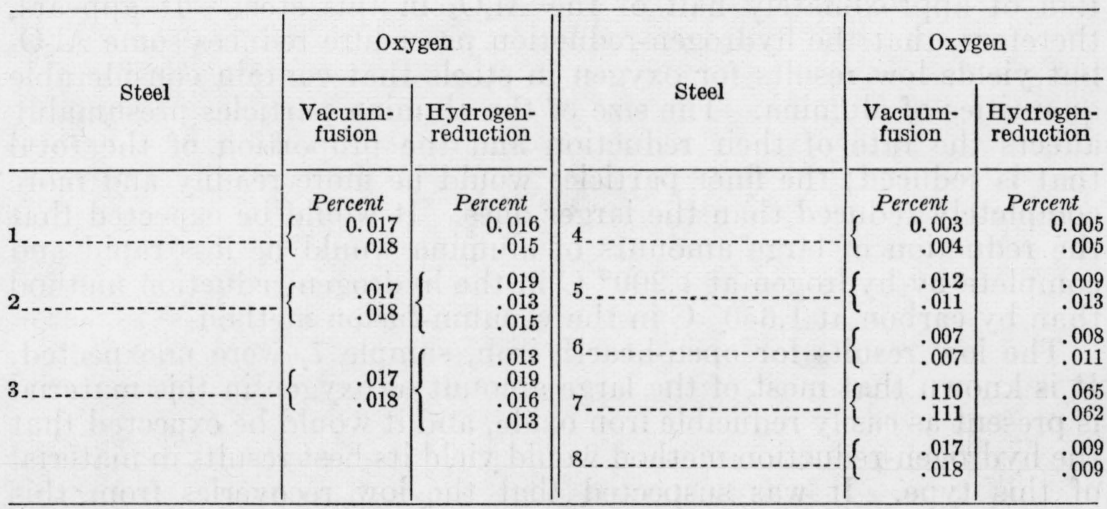

The vacuum-fusion results are in excellent agreement with those previously obtained from other samples of these steels, confirming the uniformity of the materials and permitting comparison of results obtained from the current samples with the values established by the cooperative analysis.

The results obtained in this investigation by the hydrogen-reduction method are consistently in better agreement with results by other methods than they are with those of Brower and Larsen who used the same method. We are unable to explain the apparent lack of reproducibility of results by the modified hydrogen-reduction method, as indicated by lack of agreement between our results (table 2) and those reported by Brower and Larsen (table 1). Our apparatus and procedure were patterned after theirs, but, on the same materials, their values for oxygen are considerably higher than ours. Further work is evidently needed to establish the reproducibility of results by this method and to explain the discrepancies between our results and those obtained by Brower and Larsen.

Our determinations by the modified hydrogen-reduction method, for steels 1 to 6 , inclusive, are in very good agreement with the total oxygen values listed in table 1 but the determinations on samples 7 and 8 are lower than the total oxygen values. This indicates that the hydrogen-reduction procedure yielded correct values, although less precise than the vacuum-fusion determinations, for the total oxygen contents of steels 1 to 6 in spite of the fact that some of the oxygen in each of these steels is combined as $\mathrm{SiO}_{2}$ and $\mathrm{Al}_{2} \mathrm{O}_{3}$. The data in table 1 show that most of the oxygen in steel 5 is present in the form of $\mathrm{SiO}_{2}$, whereas the greater part of the small amount of oxygen in steel 4 is combined as $\mathrm{Al}_{2} \mathrm{O}_{3}$. Recovery of all of the oxygen in these

${ }^{4}$ H. C. Vacher and Louis Jordan, BS J. Research 7, 375 (1931) RP346. 
two steels, and in steels $1,2,3$, and 6 , means that small amounts of $\mathrm{SiO}_{2}$ and $\mathrm{Al}_{2} \mathrm{O}_{3}$ are completely reduced by the hydrogen-reduction procedure. The method therefore is a total oxygen method, at least for these six steels.

The data for steel 8 furnish further evidence of the reducibility of alumina in the hydrogen-reduction procedure, although in this case the amount of $\mathrm{Al}_{2} \mathrm{O}_{3}$ is relatively large and the reduction is incomplete. The data in table 1 show that practically all of the 0.017 percent of oxygen in steel 8 is present as $\mathrm{Al}_{2} \mathrm{O}_{3}$. The 0.009 percent of oxygen recovered by the hydrogen-reduction procedure must represent reduction of approximately half of the $\mathrm{Al}_{2} \mathrm{O}_{3}$ in this steel. It appears, therefore, that the hydrogen-reduction procedure reduces some $\mathrm{Al}_{2} \mathrm{O}_{3}$ but yields low results for oxygen in steels that contain considerable quantities of alumina. The size of the alumina particles presumably affects the rate of their reduction and the proportion of the total that is reduced; the finer particles would be more readily and more completely reduced than the larger ones. It would be expected that the reduction of large amounts of alumina would be less rapid and complete by hydrogen at $1,200^{\circ} \mathrm{C}$ in the hydrogen-reduction method than by carbon at $1,650^{\circ} \mathrm{C}$ in the vacuum-fusion method.

The low results for open-hearth iron, sample 7, were unexpected. It is known that most of the large amount of oxygen in this material is present as easily reducible iron oxide, and it would be expected that the hydrogen-reduction method would yield its best results in material of this type. It was suspected that the low recoveries from this sample might be caused by loss of body oxygen during the stripping procedure that is supposed to remove only the surface oxygen. Consequently experiments were undertaken to investigate this possibility.

A determination of both the surface oxygen and body oxygen on a sample of millings from iron 7 gave 0.069 percent of surface oxygen at $500^{\circ} \mathrm{C}$, and 0.062 percent of body oxygen at $1,200^{\circ} \mathrm{C}$, making a total of 0.131 percent. Another sample of the same millings was briquetted and analyzed for total oxygen by the vacuum-fusion method. The result, 0.138 percent of oxygen, shows good agreement between the two methods for determinations which in each case included both surface and body oxygen. If the vacuum-fusion value for oxygen in a solid sample ( 0.110 percent), is subtracted from the vacuum-fusion value for the milled sample ( 0.138 percent), the difference $(0.028$ percent), is of the usual order of magnitude of values for surface oxygen from millings of the plain carbon steels that were studied in this investigation. The fact that, in the hydrogen-reduction method, 0.069 percent of oxygen was removed at a stripping temperature of $500^{\circ} \mathrm{C}$ and only 0.062 percent was subsequently recovered at $1,200^{\circ} \mathrm{C}$ indicates that exposure of this iron to hydrogen at $500^{\circ} \mathrm{C}$ removes some of the body oxygen as well as the surface film. Even at $400^{\circ} \mathrm{C}$ the results for surface oxygen were high and for body oxygen were low. Therefore it was decided to study the stripping procedure over a range of temperatures for steels 1 (low-carbon rimming), 4 (aluminumkilled), 5 and 6 (silicon-killed), as well as for iron 7. The results of the determinations, in which the designated stripping temperatures were maintained for the regular period of 90 minutes with subsequent determinations of the body oxygen, are given in table 3. 
TABLE 3.-Effect of stripping temperature on the determination of surface and body oxygen by the hydrogen-reduction method

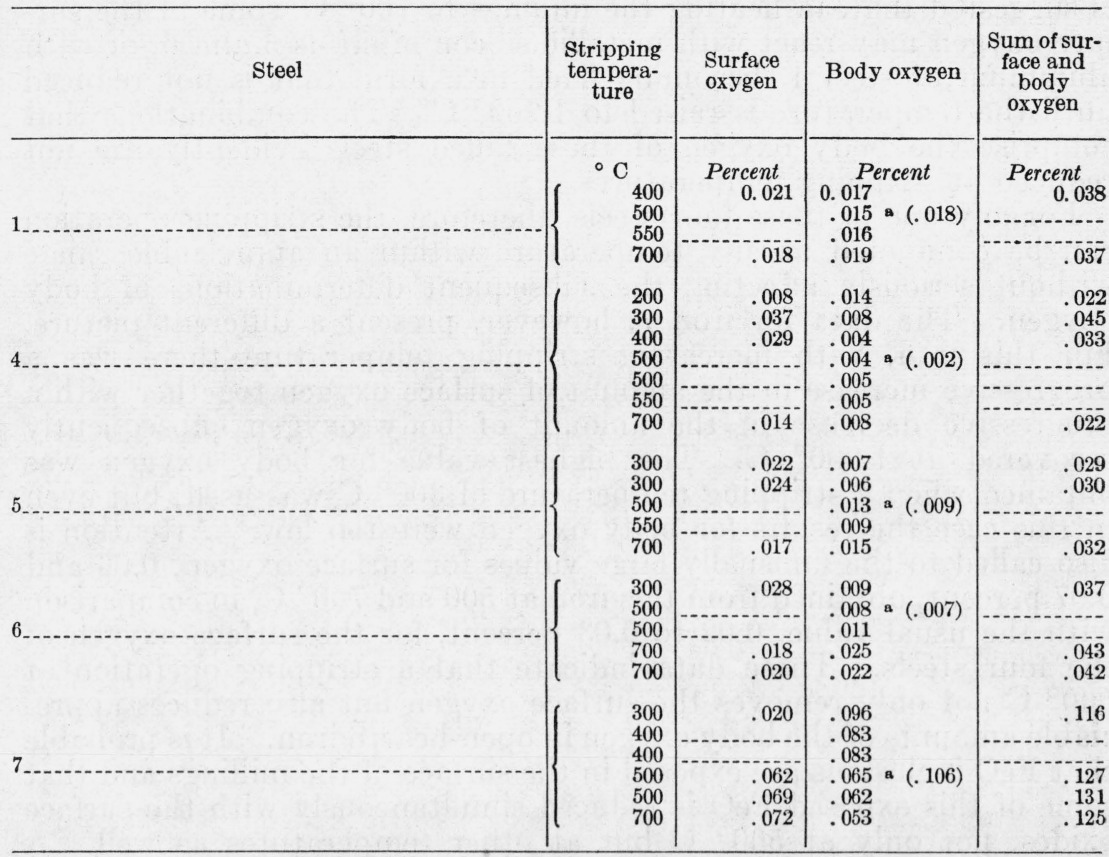

a Figures in parentheses are the values from table 1 for the oxygen contents of these steels. These values represent the oxygen in the steel; they do not include surface oxygen.

The relatively large surface area of these milled samples and the changes from day to day in the temperature and humidity of the atmosphere to which the millings had been exposed, might be expected to produce relatively large fluctuations in the values for surface oxygen from different samples. However, the values for surface oxygen lie quite consistently between 0.02 and 0.03 percent (except for iron 7 ) and the sum of body oxygen and surface oxygen stripped at different temperatures is fairly constant for each material.

Comparison of the determinations of body oxygen in table 3 with the values for oxygen contents of these steels, from table 1, show that quite satisfactory values for body oxygen are obtained from steels 1 , 4 , 5, and 6 after stripping the surface oxygen at 500 to $550^{\circ} \mathrm{C}$, as was recommended by Brower, Larsen, and Shenk. The data further show that surface oxygen can be satisfactorily removed from these steels at any temperature between 400 and $550^{\circ} \mathrm{C}$; stripping temperatures as low as $300^{\circ} \mathrm{C}$ may be used for steels 5 and 6 , but $200^{\circ} \mathrm{C}$ is too low to remove the surface oxygen completely from steel 4 , so that the subsequent determination of body oxygen is high. The surface oxygen may be stripped at $700^{\circ} \mathrm{C}$ from steel 1 , but not from steels 4, 5, and 6. It might be anticipated that the use of too high a stripping temperature would lead to low recoveries in the subsequent determination of body oxygen at $1,200^{\circ} \mathrm{C}$, because of reduction of some of the body oxygen during the stripping operation. However, this is not the case for steels 4,5 , and 6 ; for each of these and particularly for steel 6 , stripping the surface oxygen at $700^{\circ} \mathrm{C}$ is followed 
by high results for body oxygen. A possible explanation for this behavior lies in the fact that all three of these are killed steels. It is suggested that, in heating the millings to $700^{\circ} \mathrm{C}$, some of the surface oxygen may react with metallic silicon of steels 5 and 6 , or with aluminum of steel 4 , becoming fixed in a form that is not reduced until the temperature is raised to $1,200^{\circ} \mathrm{C}$. The combinations that comprise the body oxygen of these killed steels evidently are not reduced at stripping temperatures.

For any one of these four steels, therefore, the stripping operation can be conducted at any temperature within an appreciable range without seriously affecting the subsequent determinations of body oxygen. The data for iron 7 , however, present a different picture. For this iron, with increasing stripping temperature there was a progressive increase in the amount of surface oxygen together with a progressive decrease in the amount of body oxygen subsequently recovered at $1,200^{\circ} \mathrm{C}$. The highest value for body oxygen was obtained when a stripping temperature of $300^{\circ} \mathrm{C}$ was used, but even in this case the results for body oxygen were too low. Attention is also called to the unusually large values for surface oxygen, 0.06 and 0.07 percent, obtained from this iron at 500 and $700^{\circ} \mathrm{C}$, in comparison with the usual value, 0.02 to 0.03 percent, for the surface oxygen of the four steels. These data indicate that a stripping operation at $500^{\circ} \mathrm{C}$ not only removes the surface oxygen but also reduces appreciable amounts of the body oxygen in open-hearth iron. It is probable that $\mathrm{FeO}$ inclusions are exposed in the surface of the millings and that some of this exposed $\mathrm{FeO}$ is reduced simultaneously with the surface oxides, not only at $500^{\circ} \mathrm{C}$ but at other temperatures as well. A stripping temperature at which the surface oxygen of this material could be satisfactorily separated from the body oxygen, could not be found. Consequently it appears that the modified hydrogenreduction procedure is not applicable to the determination of oxygen in open-hearth iron.

\section{CONCLUSIONS}

The Brower, Larsen, and Shenk modification of the hydrogenreduction method yielded accurate results for the total oxygen contents of six plain carbon steels of the following ranges of composition: Carbon, 0.03 to 0.43 percent; silicon, 0.002 to 0.26 percent; manganese, 0.31 to 1.15 percent; and sulfur, 0.025 to 0.168 percent. The oxygen contents of these steels lie between 0.002 and 0.018 percent.

The fact that accurate values were obtained for silicon-killed steels indicates the reduction of some silicates by this method. Small amounts of alumina also were reduced but, for aluminum-killed steels that contain appreciable amounts of alumina, the hydrogenreduction method gave low results for total oxygen.

The method is not applicable to the determination of oxygen in open-hearth iron that contains relatively large amounts of easily reducible iron oxide, because of inability to separate the surface oxygen from body oxygen in this material.

The precision of determinations by the modified hydrogen-reduction method for the determination of oxygen in steels, is usually of the order of \pm 0.003 percent.

Washington, April 22, 1938. 